\title{
A formação de grupos de midiativismo no Rio de Janeiro
}

\author{
Marcelo Ernandez Macedo \\ Flávio da Rocha Pires Silva \\ Alessandra Cardoso
}

\section{Introdução}

É consenso que o surgimento recente de diversos coletivos de mídia independente no Brasil representa uma inovação tanto na linguagem jornalística quanto no sentido de uma distribuição de poder mais equânime no campo da comunicação. Ao transmitirem pela internet em tempo real as manifestações de junho de 2013, oferecendo pontos de vista alternativos às mídias hegemônicas, alguns destes novos sujeitos evidenciaram a parcialidade do modelo convencional de cobertura jornalística, sempre voltado para a manutenção da ordem, do comodismo e, portanto, do status quo; e, ao mesmo tempo, mostraram também como esses veículos estão distantes das mobilizações sociais em quase todas as suas dimensões e sentidos.

Ainda sem tradução para outras línguas, esse fenômeno vem sendo chamado no Brasil de midiativismo, termo que aos poucos se populariza ao ser utilizado tanto pelos seus participantes, quanto pelo senso comum e os estudiosos do tema. A palavra aponta para uma mídia que se caracteriza pelo ativismo e, nesse sentido, reivindica um novo paradigma para o jornalismo, contrapondo-se à tradicional proposição de imparcialidade e/ou isenção na cobertura dos fatos. A grande maioria dos grupos que se qualifica como midiativista assume e afirma a sua parcialidade ideológica a favor dos movimentos e mobilizações que reivindicam melhores condições de vida, igualdade social e o fim de uma série de preconceitos que prejudicam diversos tipos de minorias. $\mathrm{O}$ ativismo destes grupos vem sendo importante não só em termos da produção de novos tipos de conteúdos, mas também na sua capacidade de mobilização social para a participação política. 
Mas a adoção deste termo não é unanimidade entre os coletivos de mídia que vem atuando pela internet. Há aqueles que, presentes na cena da comunicação muito antes das jornadas de junho de 2013, afirmam já fazerem parte de mídias ativistas há muito tempo, questionando o que há de novo na adoção do termo. Questão esta que ganha fundamento ao verificar-se a trajetória das mídias alternativas no Brasil, que remonta pelo menos a meados do século passado, com o surgimento de periódicos patrocinados pelo Partido Comunista; passa pelo período da ditadura militar, quando aparecem diversos veículos e populariza-se esse o termo "comunicação alternativa"; e se fortalece na década de 1980, aos auspícios do sindicalismo e do surgimento de mídias locais, que mais a frente vem cunhar o termo "comunicação comunitária". Por outro lado, dados os usos que este termo vem adquirindo, fica claro também que a emergência do termo midiativismo está associada à expansão da internet e das redes sociais como canais de comunicação. Talvez resida aí a novidade principal que justifique este novo qualificativo para os grupos que se contrapõem à mídia convencional.

E vale ressaltar também que o midiativismo não é um fenômeno essencialmente coletivo. Relacionado ou não às jornadas de junho de 2013, surgiram também indivíduos que, por diversos motivos, preferem atuar isoladamente produzindo e veiculando conteúdo jornalístico pela internet. Essa atuação dá-se nos mesmos moldes dos coletivos de mídia, no sentido destes sujeitos promoverem também a transmissão de eventos em tempo real, análises políticas, esquetes de humor, mêmes e sites de notícias locais e/ou de caráter temático ou de um espectro mais amplo.

Atue de forma coletiva ou individual, o midiativista ganha popularidade na cena social, sendo cada vez mais reconhecida a sua relevância política. E, nesse sentido, há uma enorme tendência, tanto para o senso comum jornalístico como para a própria academia, à naturalização dessa figura. Muitas vezes vistos como heróis, salvadores da pátria ao esclarecerem as distorções da mídia comercial, parece que estes sujeitos detém poderes especiais, o que lhes confere carisma no sentido weberiano. É como se eles sempre estivessem estado ali e, só agora, com a expansão da internet, sua atuação se fizesse presente.

Mas como surgiu esse fenômeno que estamos chamando de midiativismo? Quem são esses sujeitos que, atuando de forma isolada ou coletiva, estão se dispondo a produzir e veicular pela internet novos conteúdos? Quais as suas motivações para isso? Como, de que forma e com que recursos fazem isso? Qual a sua capacidade de sustentabilidade e, a partir daí, de expansão enquanto fenômeno de comunicação? Essas questões parecem preocupar também um dos principais teóricos que vem refletindo sobre as mobilizações sociais nas últimas décadas, o espanhol Manuel Castels. No final do prefácio do livro em que analisa os movimentos sociais mais recentes ocorridos em diversas partes do mundo, o autor lança as seguintes questões e proposições sobre as mesmas (Castells, 2013: 20-21): 
De onde vêm os movimentos sociais? E como são formados? (...) os movimentos sociais têm um conjunto de causas estruturais e motivos individuais para se erguer contra uma ou várias dimensões da dominação social. Mas conhecer suas raízes não responde à questão do seu nascimento. Uma vez que, na minha opinião, os movimentos sociais são a fonte da mudança social, e portanto da constituição da sociedade, essa questão é fundamental.

A tendência da bibliografia que analisa a formação da ação coletiva (ou de movimentos sociais) é identificar as preocupações sociais ou correntes ideológicas que fundamentam a atuação destes grupos como explicação para o seu surgimento. Esse equívoco, recorrente na bibliografia que trata dos "novos movimentos sociais", de imputar a priori a indivíduos concepções ideológicas de caráter institucional, já foi apontado diversas vezes por uma bibliografia que compreende, assim como Castells, que os movimentos sociais são formados antes de tudo por indivíduos, despidos a priori destas convicções ideológicas institucionais e envoltos em determinados contextos sociais, carregando consigo trajetórias pessoais e singulares, que reunidos ajudam a explicar suas motivações (citar autores). Segundo Castells (2013: 21):

Há geralmente um punhado de pessoas, às vezes apenas uma, no início de um movimento. De hábito, os teóricos chamam essas pessoas de agências. Eu as chamo de indivíduos. Então, temos que entender a motivação de cada indivíduo: como estes indivíduos constituem uma rede conectando-se mentalmente com outros indivíduos e por que são capazes de fazê-lo; num processo de comunicação que, em última instância, leva à ação coletiva.

Este artigo pretende responder a este conjunto de questões relacionadas à formação do fenômeno do midiativismo. Estaremos aqui chamando de midiativista o grupo ou sujeito isolado que produz e/ou organiza conteúdo para veicular na internet. E, seguindo a tradição teórica apontada acima, para responder a estas questões examinaremos as trajetórias sociais, motivações pessoais e inserções institucionais de "midiativistas".

Parte do material de campo coletado é oriundo das filmagens do documentário Mídia em movimento, que acompanhou durante dois anos (entre junho de 2013 e junho de 2015) quatro grupos de midiativismo da região metropolitana do Rio de Janeiro. Ao longo desse período, tivemos contato também com outros coletivos de mídia independente, com midiativistas que atuam de forma isolada e, após as filmagens, realizamos entrevistas com dois outros coletivos. A análise sobre a formação de grupos de midiativismo será feita com base nesse material de campo.

Além desta introdução, o artigo está estruturado em três partes: na parte seguinte, faremos a reconstituição do fenômeno do midiativismo em escala mundial, 
que remonta às manifestações em Wall Street, em 1999, contra as medidas a serem tomadas em uma rodada de negociações da Organização Mundial de Comércio. Nossas principais referências para essa reconstituição são o próprio Castells e, principalmente, a dissertação de Fleischman (2006). Em seguida, discutiremos o material coletado em nossas pesquisas de campo na tentativa de lançar luzes sobre a emergência do fenômeno no Rio de Janeiro; e, em uma última parte, teceremos nossas conclusões sobre todo esse material de pesquisa.

\section{O surgimento e desenvolvimento do midiativismo em escala mundial}

Antes de falar sobre a história do midiativismo, é importante identificar já nas décadas de 1970 e 1980 o surgimento de frentes de luta específicas como: os movimentos pela paz; o ambientalismo, o feminismo e as minorias sexuais e étnicas que se distinguiam por não responder à um projeto político pré-definido. Há o reconhecimento de uma pluralidade de lutas que não se enquadram na forma tradicional de resistência da esquerda, baseada na estrutura de poder vertical dos partidos políticos e sindicatos.

É notável que desde o início dos anos 1990, os movimentos sociais, ativistas políticos e organizações não governamentais começaram a formar redes e se apropriar das novas tecnologias de informação para utilizá-las como ferramenta de ação política. A rapidez, a interconexão e o baixo custo dos recursos da Web facilitaram a proliferação dos discursos e ações alternativas nos aspectos local e global. Esta chamada "organização em rede" promove simultâneamente a coordenação de ações coletivas em diferentes lugares do mundo que se identificam por causas específicas e a sua diversificação. Traremos a seguir os principais exemplos das primeiras práticas midiativisitas pelo mundo.

Houve um grande desenvolvimento de mecanismos de auto expressão a partir da insurreição Zapatista de 1 de janeiro de 1994, que ocorreu quando o NAFTA (Acordo de Livre Comércio da América do Norte) entrou em vigência. A presença dos zapatistas ${ }^{1}$ na internet começou a partir da divulgação de seus comunicados em vários idiomas e foi estendida através de listas e grupos de discussão, páginas de apoio à luta indígena (incluindo a luta zapatista) e a análise e documentação dos meios alternativos, que levou parte da opinião pública a tomar conhecimento das mobilizações sem depender dos meios comerciais. O "projeto de meios de comunicação em Chiapas" (CMP) ${ }^{2}$ foi uma iniciativa de vídeo indígena implementada desde 1998 nas comunidades locais de Chiapas, mediante o apoio financeiro de organizações mexicanas e estadunidenses. Este projeto tinha como objetivo dar informação e formação aos próprios moradores do local com o uso de ferramentas multimídias, para que eles próprios pudessem desenvolver de forma coletiva e em comunidade os recursos para se comunicar autonomamente, documentando suas 
formas de luta social e pensando também na memória das comunidades indígenas, fazendo valer o lema "dar voz aos que não tem voz" e trazendo a experiência ativista na web para mais próximo deles.

A habilidade de Marcos como comunicador e conhecedor dos meios de comunicação, a capacidade dos zapatistas em se manterem na mídia e o interesse despertado em todo o mundo, alimentando constantemente as redes eletrônicas com informações de e sobre Chiapas, fizeram com que as reivindicações básicas dos insurgentes zapatistas e a realidade das populações indígenas da região circulassem em escala global, chamando a atenção não só da sociedade mexicana, mas de grande parte da população mundial para as demandas seculares daqueles povos até então esquecidos. (Ortiz, 2005: 178).

Mas, talvez o acontecimento mais marcante pelas suas dimensões nessa trajetória história do midiativismo seja o movimento de Seattle, considerado por Fleischman (2006) como o ponto de partida do movimento global de midiativismo. O movimento consistiu em uma série de protestos massivos nas ruas de Seattle, nos fins de novembro de 1999 , em que mais de 50 mil pessoas provenientes de diferentes lugares do mundo se manifestaram durante três dias contra uma reunião ministerial da Organização Mundial do comércio (OMC). O bloqueio da "rodada do milênio" da OMC foi uma vitória que proporcionou uma inesperada visibilidade mundial, provocando um forte impacto político e ganhando repercussão internacional nos meios de comunicação. A Indymedia se tornou conhecida como "o movimento dos movimentos" por articular os movimentos midiativistas e fazer publicações e transmissões ao vivo de vídeos em seu site oficial, que era o principal veículo de comunicação dos manifestantes, que atuavam também hackeando servidores da OMC.

Surgia naquele momento o primeiro site que permitiu às pessoas reportarem o que estava acontecendo sem precisar de intermediários. O site foi útil para os manifestantes do movimento antiglobalização noticiar suas lutas, sendo o primeiro a utilizar a publicação aberta com o objetivo claramente político de contra hegemonia. A mobilização era composta por adeptos do movimento estudantil, anarquistas, ambientalistas, feministas e outros interessados em combater as tendências da OMC.

Três anos depois, no contexto de dificuldades socioeconômicas que a Argentina se encontrava, em que pobres e periféricos viviam sob uma forte onda de miséria e desemprego em decorrência das políticas neoliberais de Carlos Menem, surgiu uma articulação de desempregados, o denominado movimento dos piqueteiros. ${ }^{3}$ Uma das principais mobilizações ocorreu no dia 26 de junho de 2002, durante um piquete organizado pelo Movimento de Trabalhadores Desempregados Aníbal Verón (MTD) em "Puente Pueyrredón", uma das entradas mais importantes para a cidade de Buenos Aires. Nesse ato morreram dois manifestantes piqueteiros assassinados. 
A notícia das mortes foi dada em primeira mão pela Indymedia, ${ }^{4}$ já que os membros do MDT entraram em contato para denunciar a brutal repreensão policial que provocou o ocorrido. Os meios tradicionais apoiavam a versão do governo que atribuía as mortes a um enfrentamento entre grupos piqueteiros. A Indymedia conseguiu a partir de sua cobertura fazer circular as provas fotográficas que comprovavam a responsabilidade do governo e da polícia Bonaerense pelos assassinatos e fizeram com que estes admitissem a culpa antes mesmo do julgamento. Nos anos seguintes, eles acompanharam detalhadamente todo o processo judicial da morte dos piqueteiros e toda essa documentação pode ser encontrada em sua página oficial.

Em 11 de março de 2004, ${ }^{5}$ ocorreu um bombardeio em Madri e, três dias depois, as eleições presidenciais na Espanha. Nesse período de tempo, o uso da internet e das mensagens de texto aumentou em $30 \%$ e $40 \%$. Nesse caso, buscavam informações sobre os responsáveis pelo ataque, pois a versão oficial do governo e dos meios de comunicação atribuiam responsabilidade à ETA, sendo que a Al Qaeda já havia assumido para o governo a responsabilidade pelo atentado. $O$ resultado dessas eleições favoreceu amplamente à oposição do governo, dando vitória ao Partido Socialista. Podemos dizer que a rápida difusão de informações sobre o atentado através dos celulares foi analisada como uma forma de resistência midiática, em oposição às primeiras versões do governo para o atentado. Os ataques também foram acompanhados e noticiados pela Indymedia a partir do seu site oficial.

Outro importante ator na história do ativismo digital é o "Fórum Social Mundial" (FSM), encontro em que pessoas dos mais diferentes lugares, ideologias, etnias e grupos juntam-se para discutir e traçar estratégias para tornar sua luta evidente, assim atingindo seus objetivos. Todo este processo só foi possível graças ao uso da internet pelos organizadores. O primeiro ocorreu na cidade de Porto Alegre (Rio Grande do Sul/ Brasil), entre 25 e 30 de janeiro de 2001, com o objetivo de se contrapor ao Fórum Econômico Mundial de Davos. Destes encontros, ocorridos anualmente desde então, criou-se a plataforma virtual "A Ciranda", que tem objetivo ser um espaço em que os meios alternativos, comunitários e agências de notícias independentes podem facilitar suas coberturas produzidas no evento. "A Ciranda" tornou-se parte integrante do Conselho Internacional do Fórum Social Mundial para contribuir e dialogar sobre a construção de uma política de comunicação do ponto de vista de participantes dos movimentos de comunicação, das mídias alternativas e comunicadores/sociais (além de jornalistas, inclui pessoas que atuam em blogs, redes, movimentos culturais e de software livre ${ }^{6}$ ). (A Ciranda, 2009)

No livro Redes de indignação e esperança, Manuel Castells apresenta seis movimentos sociais, localizados em diversas partes do mundo, que utilizaram as redes sociais e a internet como meios de difusão do descontentamento em relação ao sistema governamental hegemônico e de convocação para ações urbanas, que complementavam as mobilizações. Comentaremos três dos movimentos analisados pelo autor, um de 
cada continente, começando pela África (o caso tunisiano, onde se iniciou a Primavera Árabe), passando à Europa e voltando à América do Norte.

A Tunísia é considerada por Castells (2013: 25) como a precursora da utilização da mídia como forma de ativismo. O movimento teve início numa cidade situada na região central da Tunísia. No dia 17 de dezembro de 2010, um jovem vendedor ambulante, chamado Mohamed Bouazizi, ateou fogo em seu próprio corpo diante de um prédio do governo, como último grito de protesto contra a humilhação que consistia no confisco frequente de sua bancada de frutas e verduras pela polícia local. Graças à dimensão proporcionada pela conexão em rede, a sua autoimolação foi o estopim para o desencadeamento de uma onda revolucionária em todo o país. O registro do ato foi compartilhado pela internet, dando início a uma série de atos simbólicos que representavam o descontentamento dos jovens e que estimulavam a bravura dos mesmos. Não tardou para que o descontentamento e a bravura culminassem em protestos que bradavam pelo afastamento de todo comando do governo, exigiam liberdade política e de imprensa e pediam eleições democráticas.

A utilização da internet tornou-se ferramenta eminente no processo de mobilização dos manifestantes, que compartilhavam em rede os vídeos dos protestos e as reações violentas da polícia, além de convocarem a população aos atos nos locais públicos das cidades de todo país. Eram organizados fóruns que desenvolviam longos e intensos debates ao ar livre, discutindo pautas que aspiravam à democracia, à educação de qualidade e a mais empregos (já que grande parte dos jovens manifestantes eram desempregados). Dessa forma, Castells afirma que: "a conexão entre a comunicação livre pelo Facebook, Youtube e Twitter e a ocupação do espaço urbano criou um híbrido espaço público de liberdade que se tornou uma das principais características da rebelião tunisiana, prenunciando os movimentos que surgiriam em outros países" (Castels, 2013: 25-47).

No Ocidente, a crise que assolou a Europa despontava consequências severas na Espanha. O desemprego atingiu 22\%, e 47\% entre os jovens. O governo promoveu cortes orçamentários profundos nas áreas de saúde, educação e serviços sociais. E a população passou a desprezar políticos e partidos, simbolizando a descrença no progresso socioeconômico do país.

Uma pequena rede de cidadãos ativos em diversos movimentos e causas, de várias cidades espanholas, criou um grupo no Facebook, intitulado "Plataforma de Coordenação de Grupos Pró-Mobilização Cidadã”, que logo se transformou em um novo grupo no Facebook, denonimado Democracia Real Ya, cujo principal objetivo era a consolidação de debates e ações. A plataforma se estendeu para um fórum, um blog e uma lista de e-mails. Alguns núcleos desenvolviam atividades pessoalmente, toda semana (como em Barcelona). Centenas acompanhavam a mobilização virtual e alguns participavam dos encontros. Clamavam por uma democracia mais 
representativa e um governo que estivesse a serviço dos interesses dos cidadãos e não dos banqueiros.

Como forma de concretização da indignação que estava somente em campo virtual, convocaram a população para uma manifestação com o slogan "Democracia Real Ya! Ocupe as ruas. Não somos mercadorias nas mãos de políticos e banqueiros!". O apelo, ignorado pela mídia, repercutiu nas redes sociais, como Facebook, Twitter, Tuenti etc. A divulgação obteve um logro bem-sucedido: 50 mil pessoas em Madri, 20 mil em Barcelona e 10 mil em Valência. As manifestações tiveram espaço em mais 50 cidades, com menor expressão. Após as manifestações em Madri e em Barcelona, os ativistas organizaram fóruns e debates sobre temas nas praças mais simbólicas das cidades (Praça Puerta del Sol e Praça Catalunya, respectivamente). Os participantes atualizavam seus perfis no Twitter, com tuites sobre a situação do movimento e convidando seus amigos. Milhares de pessoas compareceram nos primeiros dias. Muitas delas levaram sacos de dormir com a finalidade de acampar no lugar ocupado (o que ficou conhecido como acampadas).

No final da primeira década deste século, os Estados Unidos também mergulharam em um caos financeiro que colocou em cheque a confiança de sua população. O mercado imobiliário naufragou, centenas de milhares de pessoas perderam suas casas, os bancos pararam de oferecer empréstimos, centenas de empresas foram fechadas, milhares de empregados foram demitidos e os salários foram reduzidos profundamente. Em síntese, o sistema financeiro estava chegando à beira de um colapso. A esperança de uma mudança definitiva depositada nos votos para Barack Obama estava se esvaindo diante do cenário caótico em que o país se encontrava. A população estava sendo tomada pelo descontentamento decorrente da má gestão financeira e a indignação preparava o solo para a centelha que estava por vir.

No dia 13 de julho de 2011, a revista Adbusters publicou em seu blog a seguinte convocação: “\# occupywallstreet. Você está pronto para um momento Tahrir? No dia 17 de setembro, invada Lower Manhattan, monte barracas, cozinhas, barricadas pacíficas e ocupe Wall Street”. A mobilização proposta pela revista via como principal demanda a exigência da nomeação de uma comissão presidencial que poria fim à corrupção em Washington. Seguida dessa manifestação, muitas outras aconteceram em todos os estados do país. Quanto mais a polícia recorria à repressão, mais vídeos dessas ações que circulavam no youtube mobilizavam os manifestantes. Em menos de um mês, as manifestações já se encontravam em mais de 600 cidades dos Estados Unidos.

Papel elementar tiveram os espaços virtuais. As redes sociais divulgavam as demandas, necessidades, a violência proveniente do Estado e as experiências vivenciadas. A vertiginosa difusão geográfica do movimento se deu por sua propagação viral na internet. Concomitantemente, a ocupação dos espaços públicos foi uma forma para os manifestantes encontrarem um ambiente de autonomia, salvos do controle ideológico e político de múltiplos agentes sociais, proporcionando debates e a formação de uma 
comunidade que compunha interesses diversos, mas que convergiam na justiça e igualdade. Portanto, ambos espaços foram imprescindíveis para a dinâmica da causa. Um não poderia existir sem o outro. Como na Tunísia e na Espanha, o espaço híbrido composto de virtual e material é o que caracterizava o movimento.

Os acontecimentos de junho de 2013 no Rio de Janeiro e no Brasil não podem ser compreendidos do ponto de vista sociológico se não levarmos em conta a trajetória que acabamos de resumir. Como vimos, desde o início da década de 1990, uma série de mobilizações em diversos continentes foram viabilizadas a partir da atuação de midiativistas que, além de oferecer abordagens alternativas à mídia convencional, foram fundamentais no processo de reunião e articulação das pessoas e grupos.

\section{O midiativismo no Rio de Janeiro}

Assim como ocorreu em diversas partes do mundo, houve no Brasil em 2013 um intenso processo de mobilização social para protestar contra a falta de representatividade do sistema político, a repressão do Estado ao direito de se manifestar e as políticas de cunho neoliberal que estavam sendo levadas à cabo pelo então governo do Partido dos Trabalhadores (PT). Embora a demanda prioritária e pontual fosse a redução dos preços das passagens de ônibus, as três demandas que acabo de apontar resumem um conjunto de pautas extremamente difuso, com as pessoas empunhando cartazes com os mais diversos tipos de dizeres. Todo esse processo só foi possível porque, desde a primeira manifestação, em abril, que contou com cerca de 100 pessoas, até o dia 20 de junho, quando caminharam mais de um milhão de pessoas rumo à Prefeitura da cidade, tudo foi registrado e veiculado em tempo real por mídias alternativas que, além de produzir esses conteúdos, convocavam as pessoas para os atos subsequentes.

Para compreender a formação do midiativismo no Rio de Janeiro, além da trajetória do fenômeno em outras partes do mundo resumida na seção anterior e de outras questões contextuais que serão levantadas mais a frente, pesquisamos as trajetórias das pessoas que fazem parte desse universo.

Um primeiro aspecto que merece destaque refere-se à trajetória familiar dos midiativistas. Pedimos para os entrevistados falarem um pouco sobre isso e, a partir das respostas dadas, percebemos alguns pontos em comum. O primeiro ponto em comum é que diversos midiativistas têm parentes que exerceram militância política ao longo de suas vidas, seja em sindicatos, seja em partidos políticos, seja em âmbito mais genérico contra as ditaduras militares instauradas na América Latina nas décadas de 1960 e 1970. Uma parte significativa dos entrevistados, de modo espontâneo, mencionou essa participação, evidenciando que, de algum modo, isso afetou suas trajetórias individuais. "Meu tio participou do sindicato dos metalúrgicos em São Paulo"; "meu pai foi exiliado", "meus pais lutaram contra a ditadura" foram falas que apareceram em nossas entrevistas. 
Outro ponto em comum em relação às trajetórias familiares é que a quase totalidade dos entrevistados tem origem em famílias que tinham uma situação econômica delicada, podendo ser definidas como pertencentes à classe média baixa. São famílias assalariadas de baixa renda que residiam em áreas periféricas da cidade e/ ou em favelas, com grandes dificuldades para subsistência, e que trabalhavam como operários da indústria ou no setor de serviços. Em função dessas dificuldades econômicas, são famílias também marcadas pela alta mobilidade residencial e profissional, ou seja, deslocavam-se com frequência, seja para garantir melhores condições de moradia e/ou de trabalho, com atuação em diversos setores.

Em função dessas dificuldades e pela condição operária, suburbana e/ou de favelado, alguns entrevistados apontaram para o aguçado senso crítico dos seus parentes em relação às realidades que vivenciavam. Alguns, mesmo não fazendo parte de coletivos ou instituições políticas, destacaram que seus pais sempre tiveram uma postura crítica em relação ao que aparece na mídia e à atuação dos nossos representantes. O seguinte depoimento resume bem o que acabamos de apresentar:

Meus avós por parte de mãe são imigrantes nordestinos. Por parte de pai, meu avô, mineiro, era mecânico no Rio quando conheceu minha avó, com origem no Morro da Providência. Sou filho único. Meus pais me tiveram cedo e parecemos irmãos. Eles nunca tiveram ligação com arte e política, mas sempre foram muito críticos em relação à política. Fomos um dos enganados com o sonho de uma suposta esquerda na presidência.

Acreditamos que essa capacidade crítica desenvolvida pela própria condição social a que estiveram submetidas essas famílias pode de alguma forma estar ligada ao desejo de oferecer aos filhos uma formação educacional que possibilite maior ascensão econômica. Esse tipo de crença foi verificada em algumas outras pesquisas que explicam a formação de movimentos sociais e a mobilidade social (Macedo, 2006; Martins, 2000; Nasser, 2001). A partir daí, temos a situação de pais que tiveram baixa formação escolar, mas que não mediram esforços para que seus filhos chegassem à universidade. A grande maioria dos entrevistados tem passagem pela universidade, como será desenvolvido em seguida.

Um último aspecto em relação à influência familiar refere-se à participação de parentes em atividades artísticas, o que de algum modo induziu esses jovens a penetrar em universos diferentes daqueles esperados para sua faixa de renda. $\mathrm{O}$ seguinte depoimento é bastante representativo disso:

Tinha uma habilidade para física, química e matemática, tava indo ali para as engenharias, mas eu vi que se eu fosse para aquele lado eu não teria autonomia sobre aquilo que eu estava fazendo. Seria mais um engenheiro, trabalharia 
em um escritório, eu faria algo que não necessariamente eu saberia pra que, pra onde ou porque estava sendo feita. E aí, meu pai é músico e eu sempre tive uma conexão com as artes, sempre gostei de imagem desde pequeno, de cinema... E aí eu passei para imagem e som em São Carlos.

Além da trajetória familiar, outros pontos da história pessoal dos entrevistados mostraram-se importantes para explicar a participação desses indivíduos em coletivos midiativistas. Conforme destacado acima, a maioria dos entrevistados teve passagem pelo ensino superior. Nessa passagem, muitos entraram em contato com ideias que os estimularam a participar de coletivos e mobilizações políticas, seja pela natureza dos cursos que fizeram (em geral na área de ciências sociais, história ou filosofia), seja pela participação em disciplinas eletivas, no caso daqueles que fizeram cursos na área de ciências exatas. Outros já haviam adquirido esse senso de participação política no ensino médio, por meio da participação em grêmios estudantis.

Não obstante muitos tenham ingressado na universidade, é recorrente também o fato de boa parte não ter concluído o curso. Essa evasão da universidade ocorreu por diversas razões: frustração com o currículo; percepção de falta de autonomia política e econômica na futura atividade profissional; dificuldades em pagar os cursos (no caso daqueles que cursaram universidades privadas); dificuldades em conciliar os estudos com a necessidade de trabalhar.

Seja de modo independente da ou somadas às formações políticas no ensino médio e/ou no ensino superior, assim como seus pais, muitos midiativistas adquiriram a capacidade crítica a partir das próprias dificuldades para a sobrevivência, tanto do ponto de vista econômico, como dos estigmas que carregam, as vezes adquiridos na própria família. Vejamos os seguintes depoimentos:

Aprendi a ler cedo e interpretar as coisas no mesmo tempo, lia muito jornal, via pouca coisa boa da favela. Ainda jovem, não conseguia emprego por conta do meu endereço. Fui, com outros amigos, vítima direta de muito preconceito e no caminho, vi muitos deles escolherem o crime como última porta do desespero. Isso já me revoltava... mas minha vida é marcada, mesmo, pelas letras dos Racionais MCs, que tocavam muito nos bares, o tempo todo, colocadas na maioria das vezes por pessoas envolvidas com o varejo das drogas ilegais.

Desde bem novinho, meu pai me aconselhava a ler os jornais, nem que fosse só a primeira página, mas nunca absorver as informações que eu lia como a verdade absoluta e sempre desconfiar de tudo. Além disso, quando vim de São Paulo aos 9 anos, minha família era muito pobre e nós, eu e meu irmão, sofríamos um grande preconceito de primos e tios por conta de nossa condição social e por sermos paulistas. Isso me magoava muito e, certamente, foi determinante para a minha formação política. 
Vale destacar também que boa parte dos midiativistas teve passagem por outros coletivos com atuação política antes de fundarem ou ingressarem nos grupos que estudamos.

Apesar de a formação do coletivo ter acontecido em 2013, alguns pessoas já se conheciam de outros espaços, lutas e organizações. Temos alguns designers que já se conheciam dessa cena artística e de criação. Alguns foram militantes estudantis ativos, durante a década de 1990 e inicio de 2000, fazendo parte da formação de coletivos como o CMI e outros grupos de mídiativismo videográfico, por exemplo, bem antes do X.

Merece também destaque a faixa de idade apontada por um dos entrevistados como predominante entre os midiativistas: 23 a 40 anos; e o fato todos os nossos entrevistados serem do sexo masculino. É perceptível que se trata de um universo ainda predominantemente masculino. Não obstante, há exceções - um dos coletivos, por exemplo, revelou que em sua composição de 15 integrantes havia dez mulheres e cinco homens - e uma tendência de equilíbrio entre os gêneros, já que as bandeiras do movimento feminista são defendidas por estes grupos e, nesse sentido, a participação de mulheres está em crescimento.

Explicado como as trajetórias familiares e individuais influenciaram na entrada dos midiativistas nos seus respectivos coletivos e, portanto, contribuíram para a formação dos mesmos - vale destacar novamente que boa parte dos entrevistados não são apenas participantes desses coletivos, mas seus fundadores, o que fornece relevo para essa dimensão individual -, cabe agora compreender como estes se formaram enquanto coletivos, ou seja, como foi possível que estes indivíduos com estas trajetórias se reunissem nesses grupos.

No processo de análise do material reunido para esse artigo, saltou aos olhos dos integrantes da equipe que o escreve o fato de que a criação dos coletivos diversas vezes foi precedida pelo sentimento de indignação dos seus fundadores frente à algum tipo de violência das quais foram vítimas. Não nos referimos aqui à violência simbólica às quais vimos que estes sujeitos foram e são submetidos ao longo de suas trajetórias, mas a algum episódio marcante, algum evento ou situação extrema de violência física, em geral cometida pelo Estado.

No caso dos grupos de midiativismo que não atuam em um território definido, mas que produzem e veiculam informações sobre diversos temas do interesse de públicos mais genéricos, vale ressaltar que boa parte desses coletivos foram criados a partir das jornadas de junho de 2013, conforme já apontado. Essas jornadas podem ser em parte explicadas pela própria repressão do Estado. Conforme aponta um dos nossos entrevistados - e a nossa participação nas jornadas confirma isso - logo a partir da segunda ou terceira mobilização pela redução das passagens foi integrada à pauta 
o direito de se manifestar - já que as forças do Estado reprimiram duramente os manifestantes com balas de borracha, bombas de gás lacrimogêneo, gás de pimenta e espancamentos desde o começo. As mobilizações cresceram rapidamente diante da indignação frente à tamanha violência exercida pelo Estado. Parte dos coletivos surgiu na esteira desse processo de crescimento do uso da força pelo Estado contra as mobilizações, no intuito de documenta-la e apresentar ao grande público versões alternativas daquelas que eram veiculadas pela mídia.

Aí a gente tava ali na frente da Prefeitura, eu já tinha participado de manifestação, a gente participou do movimento estudantil, só que ali na frente da Prefeitura a gente tomou realmente uma... uma coça bonita da tropa de choque. Bem, foi a primeira vez que vi tirar um milhão de pessoas da rua, foi um milhão de pessoas tirada da rua, na porrada mesmo, bomba, a gente até fez alguns dossiezinhos lá no Y (nome do coletivo). Você vê a Avenida Presidente Vargas inteira, tem gente que fez (filmagem) mais de cima, você vê o gás lacrimogêneo em toda Avenida, então eu nunca tinha visto aquilo, entendeu? Pô, no "Fora Collor" não teve nada disso, foram movimentos diferentes. Então, naquele dia eu tentei fotografar, eu estava com uma câmera, só que não dava pra fazer muita foto porque era muita, muita fumaça; e bala ... mas era bala de borracha pra tudo quanto é lado na Prefeitura, bomba pra tudo quanto é lado e o povo correndo do nada. Então, a partir daquele dia falei "Pô, a gente tem que filmar essas coisas", continuar isso aqui, por que o que eles fizeram aqui foi um atentado ao direito de manifestação das pessoas. Então, começou a partir desse dia. O Y começou a partir daí, fui e comprei uma câmera pra filmar e o primeiro filme que a gente fez foi no final da Copa das Confederações, aquele dia também foi triste.

O entrevistado seguiu contando que o coletivo se formou a partir da reunião de um grupo de amigos que compartilharam da mesma indignação naquele momento. Ele, sua esposa, um mexicano que conheceram nas mobilizações e outros que aos poucos foram chegando compuseram a formação inicial do grupo que se notabilizou pela publicação de vídeos que mostravam versões diferentes daquelas estampadas nos veículos tradicionais. Esses vídeos ganhavam milhares de visualizações, viralizavam rapidamente, incentivando os midiativistas a seguirem o trabalho e a formação de novos grupos.

Diante das novas possibilidades de produção e veiculação da informação a baixo custo, da indignação com a violência promovida pelo aparato policial do Estado, do descontentamento com o sistema político e com o modo como tudo isso é retratado nos veículos de comunicação convencionais, criaram-se as condições sociais necessárias para que jovens com as trajetórias individuais e familiares identificadas 
acima pudessem se reunir para formar novos coletivos de mídia que tiveram um crescimento exponencial, tanto interno - com a entrada de muitos novos integrantes - como de sua diversidade, com a sua multiplicação de acordo com as afinidades estáticas e políticas entre os interessados nesse tipo de engajamento. Na medida em que esses jovens foram percebendo que esse tipo de iniciativa estava "dando certo", na medida que os produtos audiovisuais gerados alcançavam milhares de visualizações, projetando socialmente tanto os grupos quanto seus membros, houve o incentivo necessário para esse processo de sua multiplicação.

Vale ressaltar, conforme apontado na seção anterior, que o surgimento desses coletivos que atuam pela internet ocorre também em um cenário onde já atuavam uma série de iniciativas de cunho comunitário, no sentido de estarem voltadas para a veiculação de informações para territórios específicos. E, cada vez mais, estes grupos atuavam também pela internet. Havia na cidade do Rio de Janeiro uma série de experiências de jornais e rádios comunitários que estavam em processo de migração para a internet ou que, mesmo mantendo as tecnologias originais (papel e frequência modular), passavam também a atuar pela rede.

Em geral esses coletivos estão organizados a partir de algum tipo de atividade cultural (música, poesia, cinema, teatro etc.) e têm como objetivo principal mostrar os aspectos positivos dos locais onde estão situados, em geral menosprezados ou tratados pela grande mídia como polós unicamente de violência e comércio de drogas ilegais. Vejamos a descrição de um dos entrevistados sobre o modo como se deu a formação do coletivo de midiativismo do qual este foi um dos fundadores em 2005:

O [nome atual do coletivo] surge como um coletivo como desdobramento de outro grupo que a gente tinha no subúrbio, mais especificamente na Zona Norte, onde algumas pessoas se uniram para discutir cultura, para discutir política, para discutir sociedade entorno de um grupo chamado [nome do coletivo de origem]. Esse grupo chegou a um momento de criar um blog, um site, mas no modelo de blog, e esse site tinha um nome, [nome atual do coletivo], que era justamente da ideia de caminhos alternativos, movimentos alternativos ao poder constituído, ao que está colocado na mídia hegemônica. E esse blog tinha o objetivo de divulgar textos, imagens e vídeos.

A partir de junho de 2013, com a multiplicação dos grupos midiativistas, jovens que moravam nas favelas e periferias se viram motivados a criar grupos semelhantes que respondessem às demandas locais por melhor qualidade da informação, por um tipo de informação que retratasse suas localidades de forma mais digna, apontando e denunciando também os diversos tipos de violência e omissão por parte do Estado. Como afirma um dos entrevistados, a intenção destes grupos, tanto os que já existiam quanto os novos, é a de "disputar narrativas sobre o que é a favela". Este 
entrevistado, que pertence a um coletivo formado em 2013 no período de junho de 2013 - certamente sob muita influência de coletivos midiativistas com os quais os jovens desse conjunto de favelas passaram a ter contato - explica as duas linhas de atuação do grupo:

Uma que é a comunicação de resistência, onde a gente faz o acompanhamento das situações violentas, de todo caos que está acontecendo dentro da favela, pela ótica dos direitos humanos, tentando expor essa realidade e tentando também encaminhar soluções pra toda essa situação pra uma rede de parceiros que também atuam com direitos humanos, aqui no Rio de Janeiro e no Brasil. E a outra é a publicidade afirmativa, porque a mídia hegemônica, a mídia comum, gosta muito de mostrar a violência da favela, mas a gente não consegue mobilizar, por exemplo, pra mostrar um sarau, um jogo de futebol ou alguma coisa positiva. Então a gente usa essa publicidade afirmativa pra expor que a favela tem violência, mas isso é pequeno diante de todas as coisas positivas que existem. Ai, basicamente estamos nessa linha de disputa da narrativa em mostrar o outro o lado da favela e tentar frear essa situação violenta, a partir da visibilidade.

Ainda em relação aos grupos que atuam com foco em territórios determinados - em geral favelas - sua formação muitas vezes também surge de eventos específicos ligados à violência ou negligência que leva a alguma situação de extrema dificuldade.

O Coletivo W (nome do coletivo) se firma em 2014, mas ele surgiu mesmo em 2013, quando fortes chuvas fizeram várias casas desabarem aqui no [nome do conjunto de favelas] em torno de 40 quarenta casas e várias famílias. E ai, todo mundo que desenvolve algum projeto social ou alguma atividade aqui no [nome do conjunto de favelas] se uniu pra ajudar essas pessoas.

Portanto, percebe-se que muitos coletivos, seja de âmbito comunitário ou mais genérico - formados por indivíduos com as trajetórias que já caracterizamos e dentro de determinado contexto sociopolítico - surgiram a partir de um evento que significou um ponto de inflexão, uma espécie de estopim para uma participação política mais efetiva ou sistemática por meio da produção midiática alternativa. No caso de grupos já formados, a entrada nesses coletivos também ocorreu a partir dessas situações de violência que levaram a uma participação proativa.

Então você tem todo esse aparato estatal, executivo, legislativo, judiciário que são formas de você manter o status quo da sociedade e a polícia é a força armada desse Estado, que tenta controlar as pessoas. Tudo isso eu entendia de forma 
teórica. Eu lia, as pessoas me falavam, assistia vídeo. Mas, o evento da prisão [o entrevistado contou antes que foi detido e encarcerado durante alguns dias simplesmente porque estava tentando ajudar uma amiga que estava sendo presa em uma manifestação], transformou o que era um conhecimento teórico, em algo claro, de forma prática, de forma vivida, vivenciada. Então, eu acho que foi por isso que eu decidi me tornar mais ativo pra tentar transformar a sociedade, tentar enfrentar o Estado, pra impedir que ele continue abusando das pessoas, limitando a nossa vida, matando gente, torturando as pessoas.

\section{Considerações finais}

Esperamos ter conseguido mostrar nesse artigo como foi possível a formação no Rio de Janeiro desse fenômeno conhecido como midiativismo. Para tal, foi preciso evitar as naturalizações que costumam tomar ideologias de grupos como ponto de partida para a ação coletiva. Ao invés disso, procuramos articular a trajetória do fenômeno em escala internacional com o contexto sociopolítico local e as trajetórias familiares e pessoais dos indivíduos que participam desse universo. Entendemos que só assim pudemos nos aproximar do fenômeno em toda a sua complexidade.

Em nosso percurso, pudemos compreender como o Brasil e, mais especificamente, o Rio de Janeiro, a partir de 2013, serviu de cenário para o desenvolvimento dessa nova forma de produzir informação. Para o senso comum, o que ocorreu aqui pode parecer algo completamente novo, mas a trajetória que resumimos aqui deixa claro que junho de 2013 se insere em um processo social, nos termos de Elias (2006), de desenvolvimento desse fenômeno. Acredito que pudemos mostrar que o midiativismo consiste numa transformação social de longo prazo não intencional no campo da comunicação, um fenômeno histórico que vai estabelecer novos paradigmas para a área.

Seriam importantes outros estudos como esse para verificarmos as especificidades do caso brasileiro em relação a outros países. Do ponto de vista do contexto sócio-político local, pode-se verificar que muitas vezes o surgimento de coletivos de comunicação alternativa e/ou comunitária está ligado a fatos específicos onde cidadãos e/ou coletivos são colocados em extrema vulnerabilidade em decorrência de uma situação de violência, na maioria das vezes promovida pelo Estado. Como exemplos, além do caso brasileiro, onde a demanda por poder se manifestar passou a ganhar destaque a partir da percepção da população sobre a violência da ação policial e a ausência do Estado em situações calamitosas, temos o caso dos piqueteiros na Argentina e dos jovens na Tunísia. Todos esses três movimentos ganharam impulso a partir da própria violência do Estado.

Outro ponto que merece destaque na análise de contextos sócio-políticos específicos que estimulam o desenvolvimento do fenômeno - mas que foge ao âmbito do caso brasileiro - é o engajamento de pessoas e grupos de midiativismo em campanhas 
voltadas para a defesa de interesses mais amplos, tais como grandes acordos comerciais internacionais, como foram os movimentos de Chiapas, de Seattle, de Wall Street e da Espanha. Em todos esses casos as demandas estavam voltadas para a defesa de interesses que extrapolavam o âmbito local e mais particular dos seus participantes.

Vale também ressaltar que o midiativismo ganha impulso em um contexto de claro esgotamento da forma convencional de produzir conteúdos. Na medida em que a tecnologia tornou possível a transmissão de eventos em tempo real na internet, as abordagens distanciadas, distorcidas e seletivas que caracterizam os grandes meios na cobertura de fatos sócio-políticos encontram dificuldades para prevalecer. Nessa disputa de narrativas, os meios alternativos, a partir do streaming, podem oferecer outras versões de forma quase instantânea, configurando-se assim como uma efetiva fonte contra-hegemônica. Tivemos vários exemplos nesse sentido em 2013 no Brasil e, vale lembrar da experiência espanhola, onde uma distorção na cobertura de um atentado terrorista manchou a imagem de um governo com reflexos imediatos nas urnas. Nesse sentido, podemos reforçar o argumento que o midiativismo significa uma mudança de paradigma na produção de informação.

Do ponto de vista da inserção de indivíduos nesse processo, talvez a principal contribuição dessa pesquisa, descobrimos quais as regularidades que nos permite compreender o seu engajamento e participação. Vimos que boa parte dos participantes tem referências de ativismo político na família. Percebemos que, independente desse primeiro aspecto, as próprias dificuldades socioeconômicas da família em sua origem ou da situação atual servem como motivadoras para um engajamento político. Nesse cenário, os estigmas de suburbano ou favelado, associados a outros tipos de preconceito sofridos - orientação sexual, raça e classe - reforçam essa motivação para a adesão ou formação de coletivos. O desejo de jovens de apresentar versões diferentes daquelas oferecidas pela mídia às suas realidades sociais é em geral a principal explicação dada pelos mesmos para o surgimento dos seus coletivos.

$\mathrm{E}$, vimos também que se, do ponto de vista coletivo, situações de violência do Estado estimulam o surgimento de grupos, do ponto de vista individual, experiências específicas também promovem a adesão ou um maior engajamento nesse processo. A violência do Estado, em um cenário em que as perseguições pessoais são denunciadas instantaneamente, ao invés de inibir a ação política, pode incentivá-la.

Marcelo Ernandez

Professor da Universidade do Estado do Rio de Janeiro (UERJ)

Flávio da Rocha Pires Silva Graduando da Universidade do Estado do Rio de Janeiro (UERJ) Alessandra Cardoso Graduanda da Universidade do Estado do Rio de Janeiro (UERJ) 
Recebido em fevereiro de 2017.

Aceito em junho de 2017.

\section{Notas}

1. O levante zapatista ocorreu logo após o fim da União Soviética e da queda do muro de Berlim. Os zapatistas partem da ideia de que ninguém se destaca e, a partir disso, surge sua imagem mais familiar: a dos rostos cobertos por capuzes pretos que se diferenciam dos líderes da esquerda organizada em partidos e sindicatos. Possuem porta-vozes em Chiapas e estes atendem pelo nome de "subcomandante", sendo Marcos o mais conhecido. O ícone do movimento é representado pelos "encapuchados", junto com a estrela vermelha em um fundo preto. O movimento zapatista estende a todo momento pontes de diálogo com a chamada sociedade civil, seja a mexicana ou a planetária; e aposta, desde 1997, na criação dos municípios autônomos. Enfrentam a ameaça constante dos grupos paramilitares e ainda encontram forças para colocar no ar, desde agosto de 2003, a sua Rádio Insurgente, que pode ser acessada pela Internet. Sua principal função é dar voz aos indígenas e às suas causas.

2. Chiapas é uma cidade onde pelo menos um terço de sua população é indígena, cerca de 3,5 milhões de pessoas; e mais da metade é mestiça. Há um racismo expressivo em relação aos indígenas, e até cerca de três décadas atrás os indígenas não podiam andar pela cidade de San Cristóbal. Essa exclusão era protagonizada principalmente pela igreja católica.

3. Os piqueteiros apostavam nos massivos bloqueios de pontes, estradas e ruas das cidades, por dias e até mesmo semanas. Os atos chegavam a reunir dezenas de milhares de pessoas numa mesma marcha. Desta forma, paravam a circulação das mercadorias, causando prejuízos aos empresários e obrigando os meios de comunicação a dar voz àqueles que mais sofreram as consequências das desastradas políticas econômicas dos últimos anos. A partir de assembleias populares nos bairros surgiram iniciativas como poupança coletiva: começaram a funcionar milhares de cozinhas comunitárias, padarias e hortas onde se produzia alimento barato e se gerava uma pequena renda graças à venda desses produtos para a vizinhança. O recurso arrecadado voltava para os comedores (os restaurantes comunitários). Posteriormente outras iniciativas, como creches, bibliotecas, espaços de formação política e até mesmo pequenas cooperativas têxteis, marcenarias e ferrarias. Com isto, os piqueteiros se tornam a mais importante força popular do país neste começo de século XXI e um símbolo de resistência às inaceitáveis injustiças de nosso continente. 4. http://brasil.indymedia.org/es/blue/2003/02/248237.shtml

5 http://www.midiaindependente.org/pt/red/2004/03/275855.shtml

6. O movimento software livre é um movimento social, com o objetivo de obter e garantir certas liberdades para usuários de software, ou seja, a liberdade de executar o software, para estudar e modificar o software, e para redistribuir cópias, com ou sem alterações. 


\section{Referências}

BRINGEL, Breno e MUÑOZ, Enara. Dez anos de Seattle, o movimento antiglobalização e a ação coletiva transnacional. Revista Ciências Sociais, v. 46, n. 1, p. 28-36. Porto Alegre: Unisinos, 2010.

CASTELLS, Manuel. Redes de indignação e esperança: movimentos sociais na era da internet. Trad. Carlos Alberto Medeiros. Rio de Janeiro: Zahar, 2013.

ELIAS, Norbert. Escritos e ensaios - 1. Estado, processo, opinião pública. Org. Neiburg, Federico \& Waizbort, Leopoldo. Rio de Janeiro: Zahar, 2006.

FLEISCHMAN, Luciana. Os novos meios de Ativismo na Internet: o caso dos centros de mídia da internet. Dissertação de Mestrado. Niterói, RJ: UFF, 2006.

MACEDO, Marcelo Ernandez. Zé Pureza: etnografia de um acampamento no norte Fluminense. Tese de doutorado. Rio de Janeiro: PPCIS/IFCH/UERJ, 2003.

MARTINS, José de Souza. A sociabilidade do homem simples: cotidiano e história na modernidade anômala. São Paulo: Hucitec, 2000.

NASSER, Ana Cristina A. Sair para o mundo: trabalho, família e lazer na vida de excluídos. São Paulo: Hucitec, 2001.

ORTIZ, Pedro Henrique Falco. Das montanhas mexicanas ao ciberespaço. Estudos avançados, v. 19, n. 55, p. 173-186. São Paulo: IEA/Universidade de São Paulo, 2005.

\section{Sites consultados}

A CIRANDA. A Ciranda (2016). Disponível em: https://www.ciranda.net/A-Ciranda?lang=pt_br; DIAS, Tatiana de Melo. CMI: o coletivo que fundou o ativismo digital. [S.1: s.n.]. Disponível em: http://revistagalileu.globo.com/Revista/Common/0EMI341647-17773,00;

FERNANDES, Marco. Os piqueteiros na encruzilhada | MST - Movimento dos Trabalhadores Sem Terra. Disponível em: http://antigo.mst.org.br/jornal/269/internacional; LOCATELLI, Piero. Zapatismo, vinte anos depois. CartaCapital, 1 fev. 2014. Disponível em: http://www.cartacapital.com.br/sociedade/zapatismo-vinte-anos-depois-6195.html. 


\title{
Resumo
}

O artigo analisa as condições sociais necessárias para a formação de coletivos de midiativismo no Rio de Janeiro, entendidos estes como grupos que produzem e veiculam conteúdos audiovisuais pela internet. $O$ texto está baseado em imagens coletadas para o documentário Mídia em Movimento, que apresenta o trabalho de alguns grupos de mídia comunitária e alternativa da região metropolitana do Rio de Janeiro; e em algumas outras entrevistas com midiativistas. Procuramos mostrar como a formação destes coletivos só pode ser sociologicamente compreendida se reunirmos informações sobre o contexto sócio-histórico em que se insere o fenômeno; as trajetórias individuais e familiares dos indivíduos que os compõem, com ênfase sobre seus processos de formação; e suas atuais motivações e situação socioeconômica.

\section{Palavras-chave}

Midiativismo. Comunicação alternativa. Comunicação comunitária.

\begin{abstract}
The article analyzes the social conditions necessary for the formation of collectives of midiativismo in Rio de Janeiro, understood these as groups that produce and convey audiovisual content over the internet. The text is based on images collected for the documentary Media in motion, which features the work of some community and alternative media groups of the metropolitan region of Rio de Janeiro; and in a few other interviews with midiativistas. We seek to show how the formation of these collectives can only be sociologically understood if we get information about the socio-historical context in which the phenomenon; individual and family trajectories of the individuals who compose them, with emphasis on their training processes; and their current socio-economic situation and motivations.
\end{abstract}

\section{Keywords}

Midiativismo. Alternative Communication. Community Communication. 